\title{
The Impacts of ENSO and IOD on the MSL of The Arabian Gulf and The Arabian Sea by Using Satellite Altimetry Data
}

\author{
Atyaf M. Abdul Muttalib*, Sabah M. M. Ameen, Ali B. Mahmood
}

Faculty of Marine Science, University of Basrah

Qarmatt Ali, Basrah, Iraq

Email: atyafmu@gmail.com.

\begin{abstract}
The main objective for the current research is to determine the linear trends of the mean sea level (MSL) resulting from the influence of the Southern Oscillation of EI Niño (ENSO) and the Indian Ocean dipole (IOD), which have increased in recent times due to increased global warming using satellite altimetry of MSL data. Statistical time series technique has been used. The standard ordinary univariate and bivariate linear regression method as well as Pearson correlation were used. Linear trends for the positive phase of IOD were detected on mean sea level while no linear trends of ENSO were detected in the Arabian Gulf. On the other side, linear trends of the negative phases of IOD and ENSO were detected on mean sea level in the Arabian Sea over the period 1993-2013. It is most important for climate research to provide accurate predictions of sea level rise in the coming years and plan the activities to lessen the disasters before they happen.
\end{abstract}

Keywords: satellite altimetry data, ENSO, IOD, Arabian Gulf, Arabian Sea.

\section{Introduction}

Mean Sea level (MSL) is a very important variable to study the meteorological and oceanographic status at the study region. Sea level rise has an important relationship to global and regional climate changes (Beşel and Kayıkçı, 2020). The increase in greenhouse gases, such as $\mathrm{CO}_{2} ; \mathrm{CH}_{4}$ and $\mathrm{N}_{2} \mathrm{O}$ that are released due to human activities, will increase the risk of global warming (Mahmood, 2016). MSL in the world ocean may rise about 5-30 $\mathrm{cm}$ in the year (2050) as mentioned in the report of the Intergovernmental Panel on Climate Change (IPCC) (Church et al., 2013, Alothman et al., 2014). Thus, global warming has led to many negative results, including the rise in the surface temperature of the earth as well as the rise in the temperature of sea and ocean waters. This causes water to expand and sea level to rise, it also led to the melting of the polar ice which goes to the oceans and seas, leading to a rise in the sea level (Cazenave and Cozannet, 2014). The Indian Ocean dipole (IOD) and the Southern Oscillation of EI Niño (ENSO) are important factors that affected climate in the world, which in turn causes sea level variability. The Indian Ocean dipole (IOD) and the Southern Oscillation of El Niño (ENSO) are important factors that affected by climate change in the world, which in turn causes sea level variability. That is, by increasing the occurrences of extreme El Nino events which strictly interrupted global weather patterns (Cai et al., 2014). Moreover, the changes climate could be caused the change in the extremes IOD, by the influences on the frequency and intensity of extremes in several regions simultaneously (Seneviratne et al., 2012).

The Indian dipole phenomenon can sometimes have catastrophic consequences, as the occurrence of the positive phase of IOD during 2019 was the most severe since 6 decades. It led to floods and torrential rains in the eastern regions of the African continent while high temperatures during the spring and summer months led to fires in the forests of Australia, and it is expected that The intensity of these climatic phenomena and their future effects will increase due to the increase in temperatures caused by greenhouse gas emissions (bbc., 2019). Sandeep and Ajayamohan (2018) revealed that there is relationship between ENSO and the fluctuation of rainfall on the Arabian Gulf, where the rainfall increases on all parts of the Arabian Gulf in the positive phase of ENSO, while it is less on the southern part of it in the negative and neutral phases. The IOD is thought that the remote influence of ENSO on the Middle East precipitation is through the Rossby wave activity (Sandeep and Ajayamohan, 2018). Rossby waves are long waves that result from the rotation of the earth around its axis and them moving toward the west. They are found in the Indian Ocean which play a major role in controlling sea surface temperature in the southwestern of ocean (Chakravorty et al., 2013). The wind that drives 
Rossby waves, which in turn may have an impact on sea level in coastal areas (Mirza et al., 2019). Because of the impact of these phenomena on the climate conditions in a significant way when they occur, thus, these phenomena must have an impact on sea levels and this effect may include the coasts of the Arabian Gulf and the Arabian Sea.

\section{Material and Methods}

MSL can be measured by two facilities: (1) tide gauge and (2) satellite altimeter. We used Satellite altimetry data in our current research which is considered a worldwide modern technology mostly used in the last two decades. Satellite altimeters are very accurate, these devices work to measure the topography of the oceans, the Topex / Poseidon satellite was launched in 1992 to make accurate measurements such as calculating the average time of ocean surface circulation and tidal calculation.

In this study a satellite data is used to find linear trends and compare them to the results obtained from the tidal gauge records. The data was taken from the National Oceanic and Atmospheric Administration (Siddig et al., 2019). These data represent an estimate of sea level rise measured by "satellite radar altimeters" time series and diagrams of "TOPEX/Poseidon (T/P), Jason-1, Jason-2, and Jason-3" observing the same ground path are available since 1992 (STAR, 2020). Altimetry measurements data were processed in the area from $66^{\circ} \mathrm{S}$ to $66^{\circ} \mathrm{N}$, which includes the study area. Where, applied an inverted barometer to the time series, Sea level rise calculations do not include the effects of isostatic trends on geodes, which are designed to be $0.2-0.5 \mathrm{~mm} . \mathrm{y}^{-1}$ when the global mean is calculated (STAR, 2020). The MSL linear trend should be calculated as a function of time and space and should be removed (detrended) before the calculations of correlation and regression coefficients. The linear correlation value between the $(\mathrm{X})$ and $(\mathrm{Y})$ variables is measured by the Pearson correlation coefficient $(R)$ which is represented by the following relationship (Mahmood, 2016):

$$
R=\frac{n \sum_{i} x_{i} y_{i}-\sum_{i} x_{i} \sum_{i} y_{i}}{\sqrt{\left[n \sum_{i} x_{i}^{2}-\left(\sum_{i} x_{i}\right)^{2}\right]\left[n \sum_{i} y_{i}^{2}-\left(\sum_{i} y_{i}\right)^{2}\right]}}
$$

Where, $n$ represents the number of $X$ and $Y$ values. The regression analysis method is used to found the relationship between two variables, one of which is the dependent variable such as (MSL) and the other is an independent variable such as (ENSO or IOD).

The detrended of all linear trends resulting from the various effects at sea level, and hence, created a new series as a function of ENSO and the
IOD by using the standard ordinary bivariate linear regression method, as in the following equations:

$$
\begin{gathered}
\operatorname{OLS}(Y=a+b X) \\
\operatorname{OLS}(Y=a+T \text { time }),
\end{gathered}
$$

Where (a) and (b) are the linear regression coefficients, $X$ is the independent variable (i.e., ENSO or IOD) and $Y$ is the dependent variable (i.e., MSL). $T$ is a linear regression trend by using the standard ordinary univariate linear regression method. The Pearson correlation coefficients were estimated between each of the resulting sea level time series with the IOD once and with ENSO again and tested if they were statistically significant. The P-value was found to be less than 0.05 that means the correlation result is statistically significant and there is an impact of these phenomena on the MSL. Then we found the linear trends for the time series of MSL at the Arabian Gulf and the Arabian Sea which the t-test result was statistically significant.

\section{Results and Discussion}

The annual time series of satellite Altimetry have been used to revealing of the linear effect of IOD and ENSO to MSL of the Arabian Gulf and the Arabian Sea over the period 1993-2013. The results indicated a significant correlation of the IOD and MSL of the Arabian Gulf, where, it was found that the value of Pearson correlation coefficient is (0.1411). That is, the positive signal indicates the dominance of the positive phase of IOD, as well as the linear trend was detected as its value was (0.00041029 mm. $\left.\mathrm{y}^{-1}\right)$. However, the results did not show a linear effect of ENSO on the Arabian Gulf, see Figure 1. On the other side, there were linear trends of both IOD and ENSO on the coasts of the Arabian Sea, in which, the Pearson correlation coefficient between the MSL Arabian Sea and the IOD was $(-0.1847)$. That is indicative to the negative phase dominance, next, the linear trend value was $\left(0.001246 \mathrm{~mm}^{-1} \mathrm{y}^{-1}\right)$. As for the ENSO, the value of the Pearson correlation coefficient with the MSL Arabian Sea was (-0.1239), which indicates the dominance of the negative phase of ENSO as well. Moreover, the value of the linear trend was $\left(0.0030785 \mathrm{~mm} . \mathrm{y}^{-1}\right)$, see Figure 2 and 3.

The results that used satellite data during the period of 1993 -2013 supports what it came up with in the tidal records, where a linear trend of IOD was detected at sea level in the Arabian Gulf but it did not notice any linear trend for ENSO on it. However, it was revealed that there were linear trends for both IOD and ENSO on the coasts of the Arabian Sea and the value of the linear trend of ENSO was higher than the IOD.

That is consistent with previous studies (Alawad et al., 2019), where, they concluded the 
close relationship between sea level in the Arabian Sea and ENSO phenomenon during the period of 1993-2017 by using the satellite altimetry. The results indicate the dominance of the negative phase of the IOD and ENSO on the coasts of the Arabian Sea, and this contradicts what it reached in the past. The reason may be due to the difference in the two study periods between the records of measuring the tides that extend for long periods that may reach in some stations for more than 50 years and the satellite altimetry data that was created from the end of in 1992. The results may be affected by the strong La Niña event that occurred in 1999-2001 (Alawad et al., 2019). It is known that the negative phase of IOD means that the sea surface temperature is cooler than normal in the western Indian Ocean, including the Arabian Sea. While, the negative phase of ENSO means the lower surface temperature of the Pacific Ocean less than the normal. As cold water is denser than hot water and thus lowers the sea level. Satellite data analysis has been conducted by some researchers (Srinivasu et al., 2017, Thompson et al., 2016), in which, they showed a decrease in MSL in the northern Indian Ocean for the period from 1993 to 2003. While it witnessed an increase in MSL for the period from 2004 to 2013 (Han et al., 2017). Han et al. (2010) emphasized in his study that sea level trends obtained from tidal data for the period 1961 to 2008 differ from the trends obtained from satellite data for the period from 1993 to 2008; this requires the need to obtain long records to obtain accurate information about sea level change. On the other hand, the neutral ENSO phase that means the

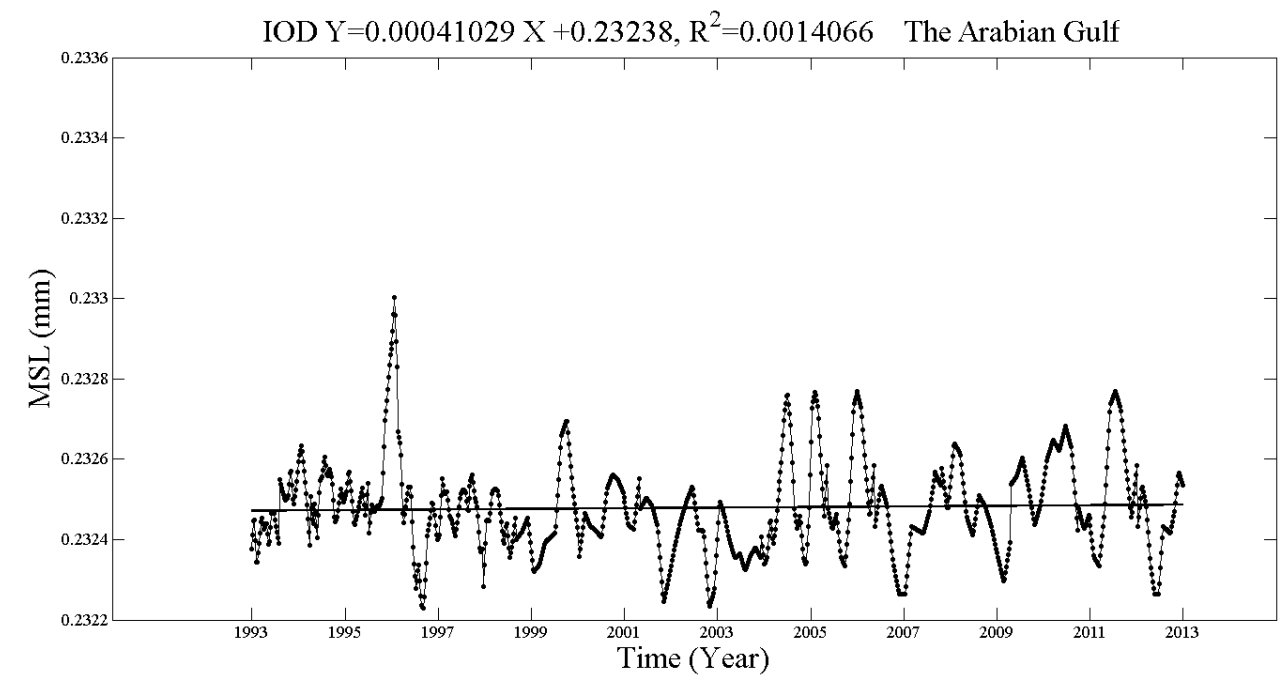

Figure 1. The linear trend of IOD in the Arabian Gulf

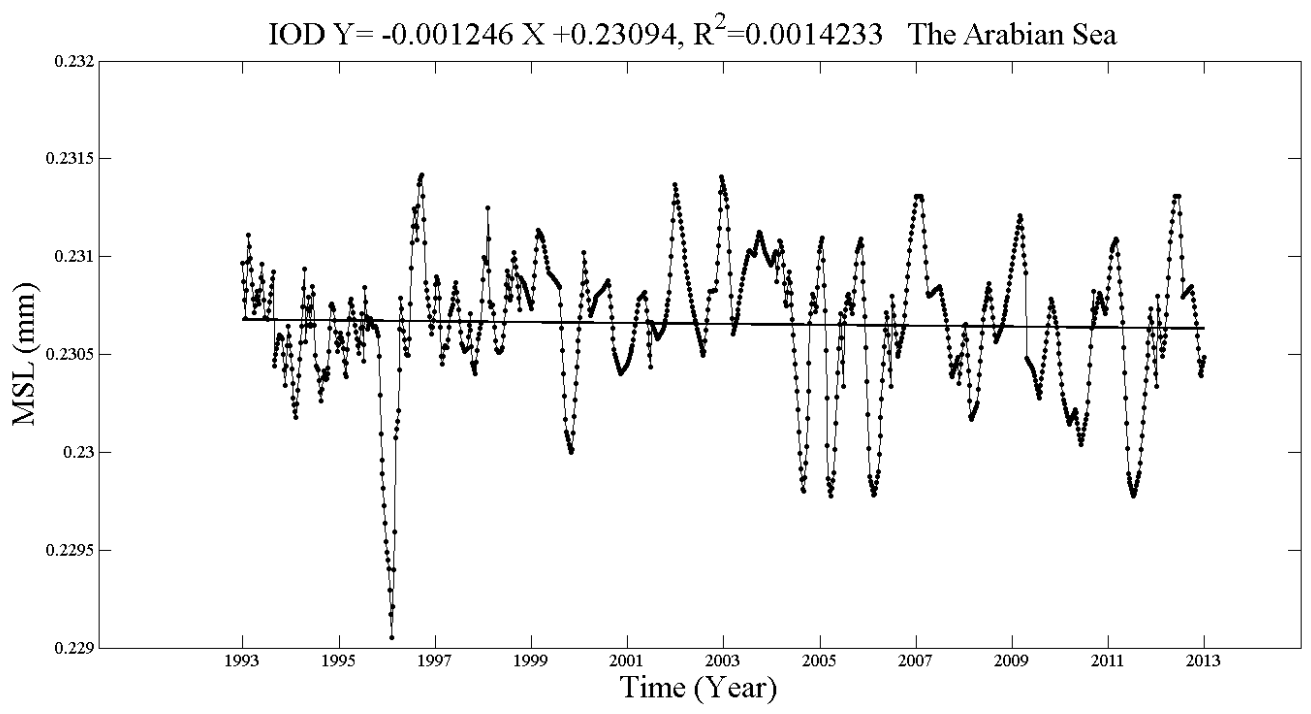

Figure 2. The linear trend of IOD in the Arabian Sea 


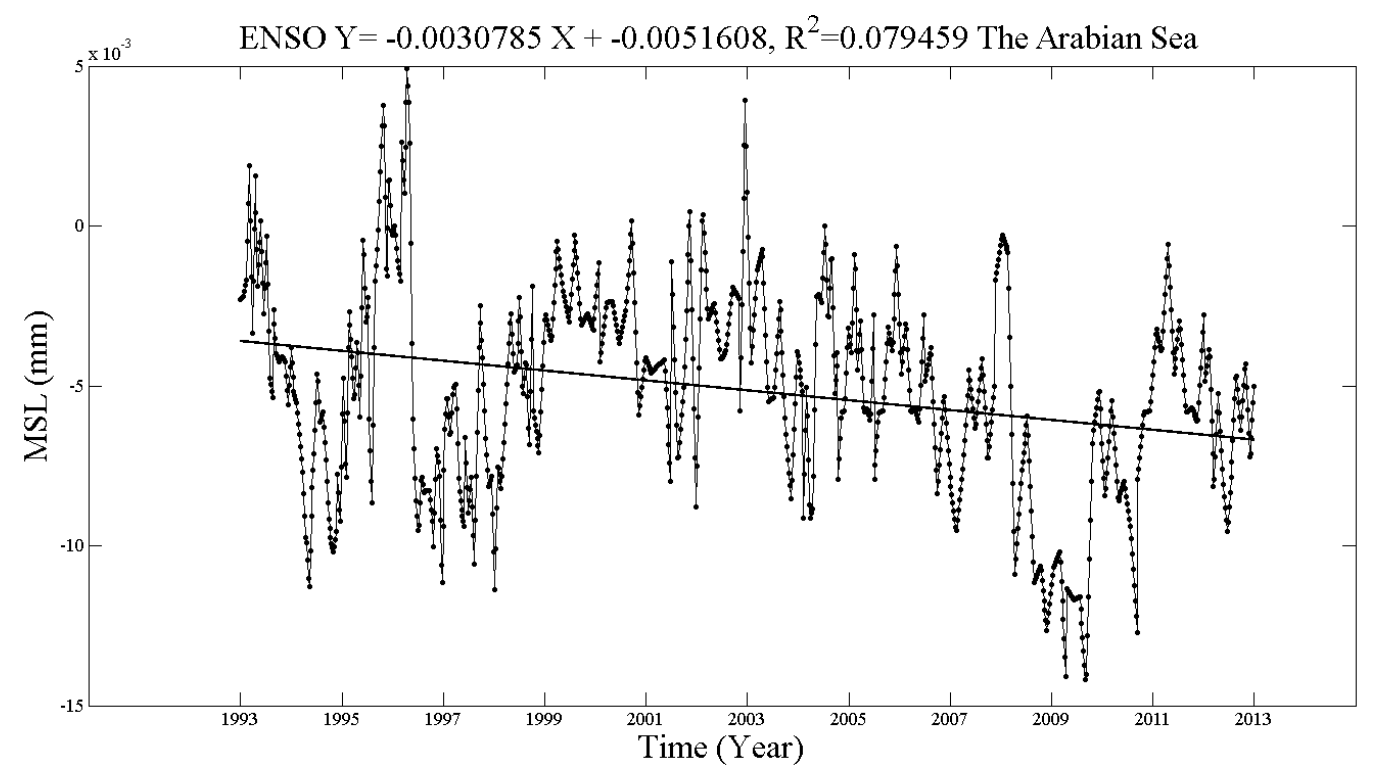

Figure 3. The linear trend of ENSO in the Arabian Sea

oscillation is neither in a warm nor cool, in which, the temperature of the ENSO of the Pacific Ocean were average. The neutral IOD phase leads to normal temperature across tropical Indian Ocean.

\section{Conclusions}

The sea level is considered one of the most important variables that are used to detect climatic fluctuations. As it is a reflection of the melting of the ice of continents and the increase in the temperature of the oceans. The obtained results indicated the prevalence of the linear effect of the positive phase of IOD on the MSL in the Arabian Gulf, which indicates the weak linear impact of ENSO on this region. However, the results indicated that the Arabian Sea was affected by the events of the IOD and ENSO together and the dominance of their two negative phases during the study period, which extends from 1993 to 2013. These important impacts may have future impacts on sea level rise in the region. The change in sea level comes as a result of climate changes, sea level began to rise during the twentieth century due to global warming and there is evidence indicating that the sea level will increase further during the twenty-first century and this causes massive damage to coastal areas. That is, lead to the concerted efforts of governments and scientists oceans to understand the processes that lead to this change in order to obtain accurate expectations to taking appropriate measures to protect those areas and take high safety measures. The obtained results increase the probability of sea level rise in the Arabian Gulf and the Arabian Sea, where it is possible to increase the frequency of the events of ENSO due to global warming.

\section{References}

Alawad, K.A., Al-Subhi, A.M., Alsaafani, M.A., Alraddadi, T.M., Ionita, M. \& Lohmann, G. 2019. Large-Scale Mode Impacts on the Sea Level over the Red Sea and Gulf of Aden. Remote Sens., 11(19):p2224. doi: 10.3390/rs111922 24

Alothman, A., Bos, M., Fernandes, R. \& Ayhan, M. 2014. Sea level rise in the north-western part of the Arabian Gulf. J. Geodyn., 81:105-110. doi: 10.1016/j.jog.2014.09.002

BBC. 2019. Indian Ocean Dipole: What is it and why is it linked to floods and bushfires? [Online]. Pablo Uchoa and the BBC's Visual Journalism teams. Available: https://www.bbc.com/news/ science-environment-50602971 [Accessed 2/2 2020].

Beşel, C. \& Kayıkcı, E.T. 2020. Investigation Of Black Sea Mean Sea Level Variability By Singular Spectrum Analysis. Int. J. Eng. Geosci., 5:33-41. doi : $10.26833 /$ ijeg.580510

Cai, W., Borlace, S., Lengaigne, M., Van Rensch, P., Collins, M., Vecchi, G., Timmermann, A., Santoso, A., Mcphaden, M. J. \& Wu, L. 2014. Increasing frequency of extreme El Niño events due to greenhouse warming. Nat. Clim. Change, 4:111-116. doi: 10.1038/nclimate2100

Calafat, F., Chambers, D. \& Tsimplis, M. 2014. On the ability of global sea level reconstructions to determine trends and variability. J. Geophys. 
Res. Oceans, 119:1572-1592. doi: 10.1002/ 2013jc009298

Cazenave, A. \& Cozannet, G.L. 2014. Sea level rise and its coastal impacts. Earth's Future, 2:15-34. doi : 10.1002/2013ef000188

Chakravorty, S., Chowdary, J. \& Gnanaseelan, C. 2013. Spring asymmetric mode in the tropical Indian Ocean: role of El Niño and IOD. Clim. Dyn., 40:1467-1481. doi: 10.1007/s00382-012-13 40-1

Church, J.A., Clark, P.U., Cazenave, A., Gregory, J.M., Jevrejeva, S., Levermann, A., Merrifield, M.A., Milne, G.A., Nerem, R.S. \& Nunn, P.D. 2013. Sea level change. PM Cambridge University Press. doi: 10.1126/science.342.6165.1445-a

Han, W., Meehl, G.A., Rajagopalan, B., Fasullo, J.T., Hu, A., Lin, J., Large, W.G., Wang, J.W., Quan, X.W. \& Trenary, L.L. 2010. Patterns of Indian Ocean sea-level change in a warming climate. Nat. Geosci., 3:546-550. doi: 10.1038/ngeo 901

Han, W., Meehl, G. A., Stammer, D., Hu, A., Hamlington, B., Kenigson, J., Palanisamy, H. \& Thompson, P. 2017. Spatial patterns of sea level variability associated with natural internal climate modes. Integrative study of the mean sea level and its components. Springer. doi: 10.1007/978-3-319-56490-6_10

Mahmood, A. 2016. The Interrelation Between the North Atlantic Oscillation (NAO) and Regulated River Discharge at the Baltic Sea Drainage Basin as well as Mean Sea Level at the Baltic SeaNorth Sea Region. Ph. D. dissertation, University of Szczecin, Szczecin, Poland. doi: 10.1007/978-94-011-5758-2_25
Mirza, B., Iqbal, M. J. \& Naz, S. 2019. Impact of Seasonal Low on Sea Level Rise. Int. J. Geosci., 10:29-38.

Sandeep, S. \& Ajayamohan, R. 2018. Modulation of winter precipitation dynamics over the Arabian Gulf by ENSO. J. Geophys. Res. Atmos., 123:198-210. doi : 10.1002/2017jd027263

Seneviratne, S., Nicholls, N., Easterling, D., Goodess, C., Kanae, S., Kossin, J., Luo, Y., Marengo, J., Mcinnes, K. \& Rahimi, M. 2012. Changes in climate extremes and their impacts on the natural physical environment. Cambridge University Press doi: 10.7916/ d8-6nbt-s431

Siddig, N. A., Al-Subhi, A. M. \& Alsaafani, M. A. 2019. Tide and mean sea level trend in the west coast of the Arabian Gulf from tide gauges and multimissions satellite altimeter. Oceanologia, 61, 401-411. doi: 10.1016/j.oceano.2019.05. 003

Srinivasu, U., Ravichandran, M., Han, W., Sivareddy, S., Rahman, H., Li, Y. \& Nayak, S. 2017. Causes for the reversal of North Indian Ocean decadal sea level trend in recent two decades. Clim. Dyn., 49:3887-3904. doi: 10.1007/s00382017-3551-y

Star, N. N. 2020. Laboratory for Satellite Altimetry / Sea Level Rise [Online]. Available: https://www.star.nesdis.noaa.gov/socd/lsa/Se aLevelRise/LSA_SLR_timeseries.php [Accessed $8 / 6$ 2020].

Thompson, P. R., Piecuch, C. G., Merrifield, M. A., Mccreary, J. P. \& Firing, E. 2016. Forcing of recent decadal variability in the Equatorial and North Indian Ocean. J. Geophys. Res. Oceans., 121:6762-6778. doi:10.1002/2016jc012132 